\title{
Clinical Archives of Bone and Joint Diseases
}

RESEARCH ARTICLE

\section{Prevalence of Vertebral Body Deformities According to Genant's Classification in Patients with Non-Traumatic Lumbar or Dorsal Acute Pain}

\author{
Guillén Astete CA*, Pijoán Moratalla C, Quiñones Torres JR and Vázquez Díaz M \\ Department of Rheumatology, University Hospital Ramón y Cajal, Colmenar Viejo, Madrid, Spain
}

*Corresponding author: Guillén Astete CA, Department of Rheumatology, University Hospital Ramón y Cajal, Colmenar Viejo, Madrid, Spain, E-mail: caranguillen@gmail.com

\section{Abstract}

The existence of a vertebral body deformity is considered a relevant finding in order to start a secondary therapeutic prevention of osteoporosis in a population at risk. However, not all vertebral body deformities are properly identified and registered. In our experience, those, less striking, can be unnoticed. One of the most common radiographic studies of the axial skeleton is the lumbar and dorsal acute pain. In this group of patients, clinicians are particularly willing to order axial $\mathrm{x}$-ray studies. Due to that, they are particularly suitable for establishing proportions of any grade of vertebral body deformities according to the Genant's scale. The aim of this study is to determine the prevalence of any vertebral body deformities in postmenopausal patients radiologically assessed due to lumbar or dorsal non-traumatic related pain. To reach our goal we performed a randomization of the registries of female patients with more than 65-yearsold who asked for medical assessment due to dorsal or lumbar non-traumatic acute pain, between January 2014 and December 2015. All included registries should have had a radiological evaluation. Vertebral body measures were performed according to Genant's scale recommendations from the seventh thoracic to the fifth lumbar vertebral body. The demographic profile of patients and the information of medical radiologic interpretation were also collected. After the randomization and excluding incomplete registries, 275 randomised registries of dorsal and lumbar pain were included (total $=550)$. Among patients with dorsal pain, we identified $62(22.5 \%), 30(10.9 \%)$ and $18(6.5 \%)$ vertebral deformities grade I, II and III respectively. Among patients with lumbar pain, we identified 31 (11.2\%), 49 (17.8\%) and $33(12 \%)$ vertebral deformities grade I, II and III respectively. Prevalence of any grade of dorsal vertebral deformity was $40.00 \%$ (Cl $34.39-45.89 \%)$, and lumbar was $41.09 \%$ (Cl 95\% 35.44 - 46.99). Lumbar vertebral body deformities grade II and III summed $17.4 \%$ while dorsal grade II and III summed $29.8 \%$. From the 93 vertebral body deformities
\end{abstract}

grade I, identified towards this study, $6.4 \%$ had been recognised and described in their corresponding clinical history during his assessment. Although our population sample is circumscribed to symptomatic patients, our results contribute knowing the prevalence of vertebral body deformities in postmenopausal symptomatic patients grade I and II and who were mostly unnoticed. Some studies have questioned the real value of Genant's grade I deformities considering them real vertebral body collapses or the effect of axial osteoarthritis. Inspite of Kellgren and Lawrence grading of osteoarthritis was homogeneous in our sample, we can not exclude this factor as a confounding one when the clinical assessment was performed during the usual clinical practice. Nevertheless, proper identification of vertebral body deformities in patients with osteoporosis is crucial to decide treatment strategies in patients with known osteoporosis.

\section{Keywords}

Vertebral osteoporotic fracture, Lumbar pain, Dorsal pain

\section{Introduction}

The clinical assessment of patients with suspect of postmenopausal osteoporosis includes a radiographic evaluation of the dorsal and lumbar skeleton in order to establish the presence or absence of vertebral body collapses $[1,2]$. In patients in risk of osteoporosis fracture, this study is particularly relevant to distinguishing primary from secondary prevention behaviours $[3,4]$. Despite the existence of many methods of quantification, the traditional semiquantitative classification method developed by Genant, et al. is still one of the most popular and accepted for establishing the presence of vertebral body collapse $[5,6]$. Genant's scale of vertebral

Citation: Guillén ACA, Pijoán MC, Quiñones TJR, Vázquez DM (2017) Prevalence of Vertebral Body Deformities According to Genant's Classification in Patients with Non-Traumatic Lumbar or Dorsal Acute Pain. Clin Arch Bone Joint Dis 1:001

Received: July 21, 2017: Accepted: September 07, 2017: Published: September 09, 2017

Copyright: (C) 2017 Guillén ACA, et al. This is an open-access article distributed under the terms of the Creative Commons Attribution License, which permits unrestricted use, distribution, and reproduction in any medium, provided the original author and source are credited. 
body deformities allows a reproducible and easy way to classify vertebral collapses. However, mild grade of deformity is still considered a controversial finding when assessing a patient at risk of osteoporosis fracture due to its relationship with degenerative processes such as osteoarthritis in both genders $[7,8]$. Due to that, decisions about therapeutic interventions on such patients are made only with grade II or III spinal body wedges.

In Spain, two important barriers are in front of our capability to predict a number of people in need of an osteoporotic secondary prevention. First, in our national setting, there is a lack of information about the prevalence of spinal body wedges of any grade because the natural access to radiologic studies is reduced to an episode of lumbar or dorsal pain as long as the patient is female and over 65-years-old. Second, the knowledge of the relevance of clinical spinal body wedges among clinicians at emergency units is widely variable. The existence of a vertebral body deformity is considered a relevant finding in order to start a secondary prevention therapy of osteoporosis in the population at risk. However, not all vertebral body wedges are correctly noticed and registered. In our experience, those, less stunning, can be certainly unnoticed. In general, when a female patient older than 65-years-old complaints by lumbar or dorsal pain, even without a traumatic process related, the diagnostic behavior in our Emergency Departments (ED) is to order a radiological study of the spine.

The purpose of the present study is to focus on this last group of patients who almost always underwent a radiological examination of the spine in order to know the prevalence of different kinds of vertebral body wedges according to the Genant's classification.

\section{Method}

\section{Population selection and sample size calculation}

This study is a sub-analysis performed from another study conducted to determine the impact of rheumatic diseases in an emergency department, which has not been publishing yet. We performed a randomization of registries of patients who asked for medical assessment in our ED due to lumbar of dorsal non-traumatic pain from January 2014 to December 2015. According to previous studies performed in our institution, $13.7 \%$ of all our patient's primary complaints are related to the musculoskeletal system and from them, about $25 \%$ due to lumbar or dorsal axial pain [9]. The randomization was performed systematically dividing the year by seasons and collecting the same amount of patients from each one. The prevalence of vertebral fractures in small cohorts studies conducted in our country is variable, from $4.3 \%$ to $17 \%$ including women older than 50 -years-old [10-13]. We performed the randomization using or electronic records of clinical registries from the ED until we reach a $120 \%$ of the estimated sample size for a non-finite theoretical population, a precision of $3 \%$ and a hypothetical estimated pessimists prevalence of $7 \%$ based on those local studies. We performed one randomization for lumbar and another for dorsal pain with the same sample size. Only registries with complete information (including topographic characteristics of pain and radiological studies) were included.

\section{Handling of information}

After randomization, we collected epidemiological and demographic data from clinical charts. The clinical description of the radiologic study was also included translating it to categorical values according to the presence or absence of vertebral body fractures or deformities. Finally, a single expert (CG) reviewed all radiologic studies and performed all measurements to establish Genant's classification of all vertebral bodies. Radiologic data used to establish the Genant's grade of deformity was the measures of the vertebral height of the anterior and posterior wall, and the height of the middle part of the vertebral body view from its lateral aspect. The rules followed to perform the classification were those exposed by Genant, et al. [5]. The expert was blinded to other clinical information and radiological reports. Inter-observer average kappa index of $95 \%$ - to classify in the same Genant category twelve different patients at two separate times - was reached in three different attempts in a previous pilot study (data not showed). All data was included into a single database to process and analysis.

\section{Data analysis}

Epidemiological and demographic data were analysed using central and dispersion-tendency statistics: average and Standard Deviation (SD). Prevalence of Genant's vertebral body fractures was expressed in percentages terms and comparing the numeric value of the fractures clinically recognised by the clinicians and those radiologically demonstrated by the expert's review.

\section{Ethical considerations}

This study is a sub-analysis of the data of another study which was approved by the Ethical Scientific Committee of our institution. Authors declare not have any conflicts of interest regarding these studies. Also, we have not had any financial support from any source to perform this sub-analysis or the main study. Finally, all the data showed in this study have not been published before.

\section{Results}

A total of 550 registries of dorsal and lumbar pain were randomised $(275$ records for each kind of complaint). Patients who consulted due to dorsal non-traumatic pain had a mean age of 75.3 SD 4.1-years-old. Patients who consulted due to non-traumatic lumbar pain had a mean age of 78.1 SD 5.2-years-old ( $P<0.001$ ). 
Table 1: Epidemiological and demographic features of patients which registries were included.

\begin{tabular}{|c|c|c|c|}
\hline & Dorsal & Lumbar & $P$ value \\
\hline Age, SD & $75.3,4.1$ & $78,15.2$ & $<0.0001$ \\
\hline Time since onset of symptoms, SD & $5.2,2.0$ & $6.3,1.9$ & $<0.0001$ \\
\hline Previous osteoporosis pharmacological treatment & $3.2 \%$ & $4.0 \%$ & 0.6486 \\
\hline Previously known vertebral body fracture & $4.3 \%$ & $7.6 \%$ & 0.1061 \\
\hline \multicolumn{4}{|l|}{ Comorbidities } \\
\hline COPD & $3(1 \%)$ & $6(2.1 \%)$ & 0.3133 \\
\hline Asthma & $4(1.4 \%)$ & $5(1.8 \%)$ & 0.7368 \\
\hline Inflammatory autoimmune disease ${ }^{1}$ & $8(2.9 \%)$ & $7(2.5 \%)$ & 0.7934 \\
\hline
\end{tabular}

${ }^{1}$ Rheumatoid artritis (5), Systemic lupus erythematosus (2), Psoriatic artritis (4) and Spondyloarthrtis (4).

Table 2: Radiologic findings after expert assessment and comparison with clinician interpretation during formal evaluation.

\begin{tabular}{|c|c|c|c|}
\hline & Dorsal & Lumbar & \multirow{2}{*}{$P$ value } \\
\hline & $N=275$ & $N=275$ & \\
\hline \multicolumn{3}{|l|}{ Genant's deformity level } & \multirow{4}{*}{$\begin{array}{l}<0.001 \text { (I vs. II and I } \\
\text { vs. III) }\end{array}$} \\
\hline I & $62(22.5 \%)$ & $31(11.2 \%)$ & \\
\hline II & $30(10.9 \%)$ & $49(17.8 \%)$ & \\
\hline III & $18(6.5 \%)$ & $33(12.0 \%)$ & \\
\hline \multicolumn{3}{|l|}{$\begin{array}{l}\text { Global accuracy between expert radiological assessment and } \\
\text { image interpretation by clinician }\end{array}$} & \multirow{4}{*}{$\begin{array}{l}<0.001 \text { (all } \\
\text { combinations) }\end{array}$} \\
\hline I & \multicolumn{2}{|l|}{$6(6.4 \%)$} & \\
\hline II & \multicolumn{2}{|l|}{$16(20.2 \%)$} & \\
\hline III & \multicolumn{2}{|l|}{$46(91.1 \%)$} & \\
\hline Previously known vertebral body fracture. Freq (\% of fracture) & & & \multirow[t]{3}{*}{ N.A. } \\
\hline II & $5 / 30(16.6 \%)$ & $9 / 49(18.3 \%)$ & \\
\hline III & $7 / 18(38.8 \%)$ & $12 / 33(36.3 \%)$ & \\
\hline
\end{tabular}

Time since onset of symptoms was 5.2 SD 2.0 and 6.3 SD 1.9 days, respectively $(P<0.001)$. History of pharmacological osteoporosis treatment was present in $3.2 \%$ and $4.0 \%$ of patients, respectively $(P=0.64)$. History of previous and diagnosed vertebral body collapse was present in $4.3 \%$ and $7.6 \%(P=0.8)$. Distribution of chronic diseases among both groups did not show differences statistically significant (Table 1 ).

Among patients with dorsal pain, we identified 62 (22.5\%), 30 (10.9\%) and 18 (6.5\%) vertebral deformities grade I, II and III, respectively (Table 2). Among patients with lumbar pain, we identified 31 (11.2\%), 49 (17.8\%) and $33(12 \%)$ vertebral deformities grade I, II and III respectively. In both cases, the difference between the proportions of Class I wedges and the others were statistically significant $(P<0.001)$. Prevalence of any grade of dorsal vertebral deformity was $40.00 \%(\mathrm{Cl} 34.39$ 45.89), and lumbar was $41.09 \%$ (Cl 95\% 35.44 - 46.99). The concordance between the detection of vertebral deformities by our study and those registered in the clinical histories of patients included in this study was $6.4 \%, 20.2 \%$ and $92.1 \%$ for grades I, II and III, respectively. All these accuracy proportions showed differences statistically significant $(P<0.001$ in all combinations). Lumbar vertebral body deformities grade II and III summed $17.4 \%$ while dorsal grade II and III summed 29.8\% $(P<0.0006)$.

As shown in Figure 1, the distribution of mild Genant's deformities was slightly more prevalent in the second lumbar vertebral body and the eleventh dorsal vertebral body while Genant's deformity grade II was more common in the first lumbar vertebra $(6.55 \%)$ and second lumbar vertebra (5.82\%). Genant's deformity grade III was not detectable in the fourth and fifth lumbar vertebrae.

\section{Conclusions}

Although our population sample is circumscribed to symptomatic patients, our main results contribute to knowing the prevalence of vertebral body deformities in postmenopausal patients which were mostly unnoticed.

The lack of accuracy showed by the low ratio of concordance between the expert opinion and the radiological interpretation of the clinicians who assessed patients also highlight the need for educative campaigns among emergency unit physicians in order to improve their capability to detect even the mildest vertebral body wedges for purposes of proper registration.

Nowadays the relevance of moderate or severe vertebral wedges is clear; however, there is some scepticism about the aetiology of the mildest level of a vertebral wedge, and for now, we do not consider it as a factor to start a secondary osteoporosis prevention therapy [14]. Prospective studies of follow up of patients with mild vertebral wedges to detect how many of them progress to significant vertebral deformities could be suitable to assess the real value of these Genant's grade I wedges. 


\section{Distribution of vertebral body level of deformity according to Genant's scale}

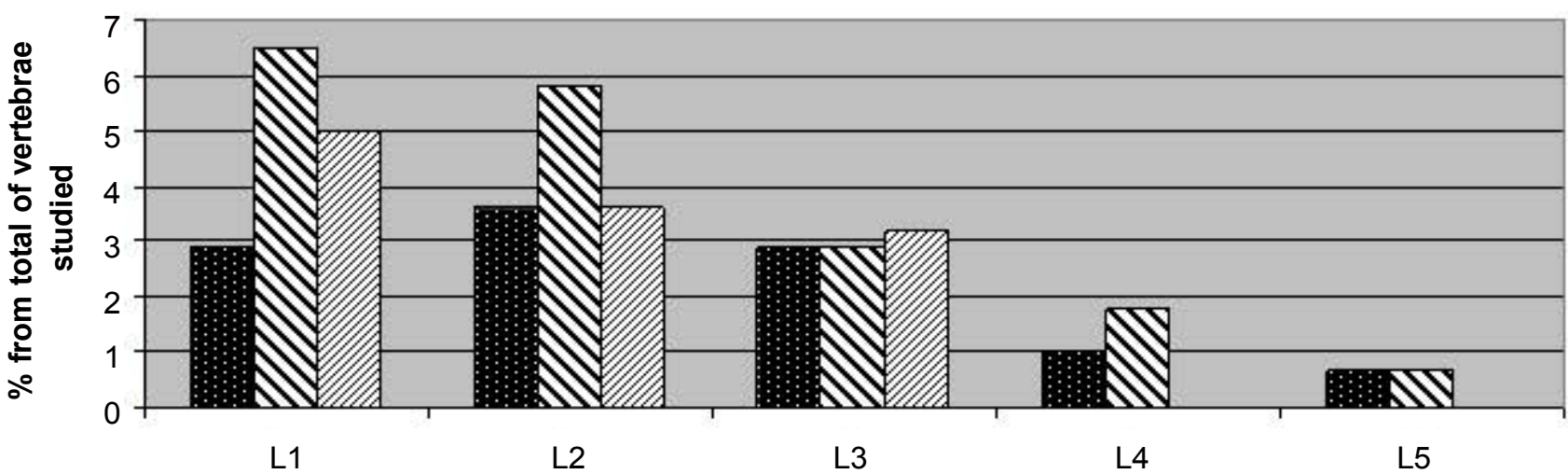

Lumbar vertebra

Grade I \$Grade II $\square$ Grade III

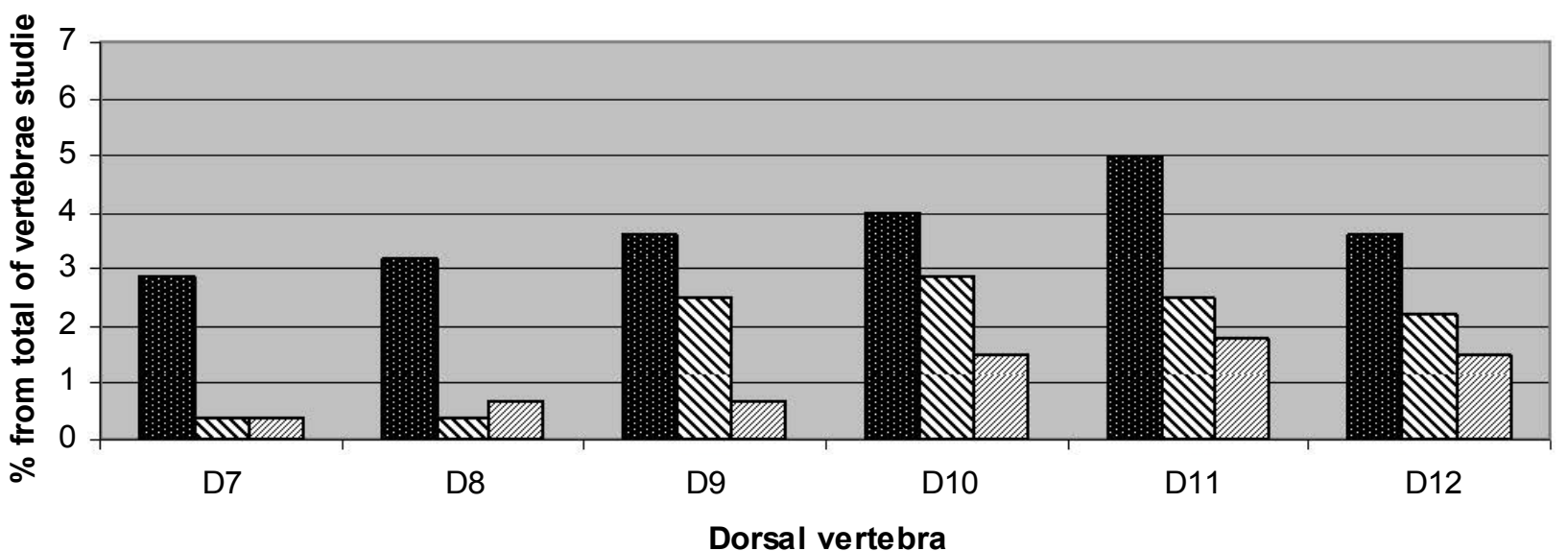

Grade I \$Grade II Grade III

Figure 1: Distribution of vertebral body level of deformity according to Genant's scale.

\section{References}

1. NIH consensus development panel on osteoporosis prevention, diagnosis, and therapy (2001) Osteoporosis prevention, diagnosis and therapy. JAMA 285: 785-795.

2. Martínez Pérez JA, Palacios S, García FC, Pérez M (2011) Assessing osteoporosis risk factors in Spanish menopausal women. Gynecol Endocrinol 27: 807-813.

3. Kanis JA, Cooper C, Rizzoli R, Abrahamsen B, Al Daghri NM, et al. (2017) Identification and management of patients at increased risk of osteoporotic fracture: outcomes of an ESCEO expert consensus meeting. Osteoporos Int 28: 2023-2034.

4. Bukhari M (2009) The national osteoporosis guideline group's new guidelines: what is new? Rheumatology. Rheumatology 48: 327-329.

5. Genant HK, Wu CY, van Kuijk C, Nevitt MC (1993) Vertebral fracture assessment using a semi quantitative technique. $J$ Bone Miner Res 8: 1137-1148.

6. Genant HK, Jergas M, Palermo L, Nevitt M, Valentin RS, et al. (1996) Comparison of semi quantitative visual and quantitative morphometric assessment of prevalent and incident vertebral fractures in osteoporosis the study of osteoporotic fractures research group. J Bone Miner Res 11: 984-996.
7. Yu W, Lin Q, Zhou X, Shao H, Sun P (2014) Reconsideration of the relevance of mild wedge or short vertebral height deformities across a broad age distribution. Osteoporos Int 25: 2609-2615.

8. Fabreguet I, Fechtenbaum J, Briot K, Paternotte S, Roux C (2013) Lumbar disc degeneration in osteoporotic men: prevalence and assessment of the relation with presence of vertebral fracture. J Rheumatol 40: 1183-1190.

9. Guillén AC, Kaumi L, Tejada Sorados RM, Medina Quiñones C, Borja Serrati JF (2015) Prevalencia de la afección musculoesquelética no traumática como motivo de consulta y su impacto asistencial en un servicio de urgencias. SEMERGEN - Medicina de Familia

10. Naves M, Díaz López JB, Gómez C, Rodríguez Rebollar A, Cannata Andía JB (2005) Determinants of incidence of osteoporotic fractures in the female Spanish population older than 50. Osteoporos Int 16: 2013-2017.

11. Kanterewicz E, Puigoriol E, García-Barrionuevo J, del Rio L, Casellas M, et al. (2014) Prevalence of vertebral fractures and minor vertebral deformities evaluated by DXA-assisted vertebral fracture assessment (VFA) in a population-based study of postmenopausal women: The FRODOS study. Osteoporos Int 25: 1455-1464.

12. Sanfélix Genovés J, Hurtado I, Sanfélix Gimeno G, Reig 
Molla B, Peiró S (2011) Impact of osteoporosis and vertebral fractures on quality-of-life. a population-based study in Valencia, Spain (The FRAVO Study). Health Qual Life Outcomes 9: 20.

13. Navarro MC, Sosa M, Saavedra P, Lainez P, Marrero M, et al. (2009) Poverty is a risk factor for osteoporotic fractures. Osteoporos Int 20: 393-398.

14. Sale JEM, Beaton D, Bogoch E (2014) Secondary prevention after an osteoporosis-related fracture: an overview. Clin Geriatr Med 30: 317-332. 